\title{
SOBRE LA DISTINCIÓN ASPECTO VS. AKTIONSART
}

\author{
Milagros Fernández Pérez \\ (Universidad de Santiago de Compostela)
}

\begin{abstract}
RESUMEN
The objective of this work is to show the uselessness of the distinction between aspect and akionsart, both from General Linguistcs and from Descriptive Linguistics viewpoint. After rewiewing the slavonic tradition (crucial to set up the most wellknown notion of aspect), and the substantial and inflective conception of Morphology, the work tries to show the necessity of a description of the grammatical (morphological) nature of aspect, based on syntagmatical implications rather than on the means through which it may be rendered (lexical, periphrasticak, inflective, etc.). Grammatical formalization of aspectual contents is thus explained through the regular syntactical repercussions which causes, e.g. specific syntactic functions, certain constitutive frameworks, restricted combination possibilities, etc.
\end{abstract}

\section{Introducción}

La abundancia de trabajos sobre el aspecto en estos últimos años no ha conducido todavía al extremo de una visión coherente e integradora respecto al carácter e importancia de la noción. Si bien podemos hallar a través de las publicaciones concepciones y enfoques sugerentes y rupturistas frente a lo que era la aproximación habitual más arraigada, no obstante sigue aún faltando una monografía sobre el aspecto que proporcione un acercamiento global serio y riguroso a esta categoría gramatical. En un sentido más particular, se echa en falta una investigación relativa a las bases en las que se asienta la noción, y a los presupuestos metodológicos que su estudio pide. Es precisamente a esa necesidad de fundamentación del aspecto a la que responden los objetivos de este trabajo.

El móvil de mi reflexión es -como ya aparece indicado en el título- la distinción tradicionalmente reconocida entre «aspecto» y «Aktionsart». Mi propósito es demostrar la inconveniencia de dicha partición, que resulta a todas luces inaceptable desde la perspectiva de la lingüística general y que tampoco es claramente rentable desde la óptica de la lingüística descriptiva. 
Que se haya aceptado y mantenido el par «aspecto»/ «Aktionsart» se explica por - entre otros- los siguientes factores.

En primer lugar, el peso de la tradición eslavística en el estudio del aspecto ha sido tal que se limitó la existencia de esta categoría en las lenguas tomando como criterio estricto el patrón de expresión sistemática del aspecto propia de gran parte de las lenguas eslavas. De este modo, sólo se contempla el aspecto en aquellos casos de oposiciones regulares dentro de un mismo paradigma verbal (las típicas parejas en español cantaba / canté; canté/ he cantado), pero no se admiten enfrentamientos aspectuales entre distintos verbos (ser / estar; conocer / saber) - para los que se recurre a la noción Aktionsart-, si bien se habla en ocasiones de «aspecto derivativo» para aquellos casos de expresión mediante afijos derivativos (besuquear) y ello aun faltando la sistematicidad en el seno de un mismo paradigma'.

En segundo lugar, la concepción de la Morfología como ámbito interesado en la configuración de las palabras a base de afijos, núcleos, temas, etc., que se identifican como segmentos fónicos en exclusiva, ha conducido a restringir la presencia de categorías morfológicas a la aparición de terminaciones y características fónicas concretas; de manera que desde esta interpretación sustancialista de las unidades morfológicas, el aspecto - como categoría morfológica que se pretende que sea- sólo se reconoce por los afijos variables sobre una misma base, y ello obliga a moverse en un único paradigma. De nuevo, el enfrentamiento entre distintos verbos se remite a la Aktionsart, pero llegan a admitirse curiosamente formas «perfectivas» (canté frente a cantaba; comí frente a comía; y también he estudiado frente a estudié) por el aspecto - dentro de un paradigma e indicadas por afijos u otros procedimientos morfológicos-, y verbos «perfectivos» (disparar, nacer) por la Aktionsart —en cuyo caso la «perfección» está expresada no por afijos sino en el significado de los verbos-.

Ya algunos autores han señalado las incongruencias debidas al entrecruzamiento de distintos factores cuando se proyecta el modelo eslavo en otras lenguas. Así, Dahl (1985) incide en el hecho de que en las lenguas eslavas - tomadas como modelo de «aspecto gramatical», y por tanto «aspecto flexivo»- se desarrolla el mecanismo de la derivación para manifestar oposiciones aspectuales. Sin embargo,

«By definition, derivation creates new lexemes» (Dahl, 1985, 27),

lo que conduciría a «Aktionsart» antes que a «aspecto», o cuando menos a la indefinición de límites entre ambas categorías. Esta falta de nitidez en las mismas lenguas eslavas que se toman como norte para aislar el aspecto frente a la Aktionsart es resaltada por Cohen $(1989,38)$ quien afirma, refiriéndose a la afijación, que

«Elle ne parvient cependant pas tracer une frontire entre les modes d'action et les aspects. En russe même, la formation des modes d'action: préfixation et suffixation, met en oeuvre les mêmes procédés et les mêmes morphemes que les formations aspectives».

De ahí la variedad de interpretación del aspecto a partir de este modelo: se habla de aspecto en casos de oposición sistemática, pero también en casos de afijación (en mayor o menor grado regular) sea cual sea su carácter (flexivo o derivativo). 
En tercer lugar, la atención ceñida a cada lengua particular y, al tiempo, el tratar de acomodar la estructura específica en cada caso a lo que es el patrón del aspecto tomado de las lenguas eslavas, impide trascender la perspectiva particularista y adoptar la óptica de lingüística general precisa para aproximarse a la cuestión del aspecto sin servidumbres ni sesgos hacia una(s) lengua(s) y respecto a unos mecanismos concretos de expresión.

En la valoración de todos los hechos señalados descansa la estructura de este trabajo, con objeto de proponer finalmente un acercamiento al aspecto como categoría gramatical desde la lingüística general; categoría que se proyecta formalizándose de diversos modos en las distintas lenguas, y cuya relevancia y sistematicidad se deduce antes por sus implicaciones sintácticas (en la combinatoria sintagmática de las palabras) que por los procedimientos y mecanismos de expresión ${ }^{2}$.

\section{El aspecto y la Aktionsart en el panorama de la Lingüística}

Si bien puede rastrearse la consideración del aspecto a través de la historia. de la Lingüística, no obstante la introducción de la «Aktionsart» parece ser obra del gramático alemán G. Herbig, quien en $1896^{3}$ propuso aquella etiqueta para referir el modo de acción del verbo, que es objetivo, frente al aspecto, que sería subjetivo. De la lingüística alemana se tomó a comienzos de siglo el concepto de «Aktionsart» para manejarlo en la descripción de las lenguas eslavas; fue, en concreto, S. Agrell el que primero lo utilizó en su trabajo de $1908^{4}$ para describir el sistema temporal en polaco. Posteriormente, se extendió su uso no sólo en la lingüística eslava sino que la trascendió y se proyectó en la linguística europea, la que - como ya he indicado - tomó como pauta de descripción del aspecto el patrón proporcionado por la gramática eslava.

\subsection{Criterios de distinción}

En un principio el criterio en que se fundamentó la Aktionsart fue el de su carácter objetivo frente al subjetivo que cabe atribuir al aspecto. Así, la Aktionsart refiere el «modo de acción» que, por sí mismo, objetivamente, corresponde a

Este modo de aproximarse al aspecto responde a lo que son los presupuestos de la concepción que defiendo sobre la Morfología (que llamo Morfémica) como ámbito de la Gramática (cfr. Fernández Pérez, 199 lb y y también 1987); y resulta así paralelo a la vía seguida para considerar el género en español (véase Fernández Pérez, 1990a). De cualquier forma, ya había adelantado (en Fernández Pérez 1990) el valor de este acercamiento al aspecto.

Cfr. G. Herbig (1896), «Aktionsart und Zeitstufe. Beitrge zur Funktionslehre des Indogermanischen Verbums», Indogermanische Forschungen, 6, 1896, 137-269.

4 S. Agrell (1908), «Aspektandrung und Aktionsartbildung beim polnischen Zeitworte: ein Beitrag zum Studium der indogermanischen Prverbia und ihrer Bedeutungsfunktionen», Lunds Universitets Arss Krift, I, IV, 2. 
cada verbo; mientras el aspecto engloba la serie de posibilidades con que el hablante, subjetivamente, puede enfocar la acción. De ahí que junto a la oposición en términos de «objetivo» vs. «subjetivo» figuren también las etiquetas de «situación»vs. «punto de vista», que pretenden asociar la Aktionsart a la propia situación reseñada por el verbo, y el aspecto a la perspectiva elegida por el hablante. Brinton $(1988,3)$ recoge la confrontación sustentada en tal criterio insistiendo en que

«Aspect is subjective because the speaker chooses a particular viewpoint, whereas aktionsart, since it concerns the given nature of the event and not the perspective of the speaker, is subjective. Aktionsart is the character of the situation named by a verb».

Al lado de estas bases más bien nocionales que soportan la distinción Aktionsart vs. aspecto en términos de «objetividad» y «situación» frente a «subjetividad»y «perspectiva», surgen en paralelo criterios que atañen a la expresión y que contraponen Aktionsart vs. aspecto por, respectivamente, su expresión léxica y su expresión gramatical.

La pauta en estos casos alcanza — como se ha señalado- a los modos de expresarse los contenidos: serán de Aktionsart cuando aparezcan asociados a los significados de los distintos verbos, por lo que su expresión se dice «léxica»; y serán contenidos de aspecto cuando se liguen a flexiones en el seno de un paradigma verbal, razón por la que su expresión se califica de «gramatical». Con palabras de Brinton (1988,3), que reflejan el sentir general a este respecto,

«Aspect is grammatical because, broadly speaking, it is expressed by verbal inflectional morphology (...), aktionsart by the lexical meaning of verbs (...)».

Aunque este segundo criterio tiene carácter formal frente al fundamento nocional del primero, sin embargo en cuanto a resultados su proyección resulta en muchos casos idéntica: hay objetividad porque no cabe elección entre dos o más formas ${ }^{5}$, sino que en los mismos verbos — por su léxico- aparecen marcadas las situaciones; hay subjetividad desde el momento en que el hablante puede optar entre diferentes formas flexionadas - gramaticales, por tanto- dentro de un paradigma. Consideraciones como las de Alarcos $(1949,77)$ referidas al español ${ }^{6}$ son suficientemente plásticas a este respecto:

\footnotetext{
5 Que no cabe la elección es relativo, ya que
}

«in order to name a situation, a speaker must conceptualize that situation in a particular way. Different speakers may choose to conceptualize the same situation differently» (Brinton, 1988, nota 2 al cap. I, pg. 247);

de ahí la desconfianza en el criterio de la objetividad para hablar de Aktionsart, y de ahí también la necesidad de aquilatar aquella base por la pauta de la expresión léxica:

no hay opción porque nos hallamos ante una única variante.

- Consideraciones que podemos hallar incluso en trabajos más recientes sobre el español, como el de Slawomirski (1983), en el que se afirma (100-101) que 
«se habla de verbos imperfectivos (saber, escribir...), perfectivos (nacer, afirmar...), reiterativos (picotear, hojear...), momentáneos (saltar, disparar...), etc., y por otra parte se habla de tiempos imperfectivos (canto, cantar...) y perfectivos (he cantado). Pero en el primer caso no se trata de valores gramaticales, lingüísticos, sino semánticos, léxicos: no existen en español dos tipos de verbos perfectivos y no perfectivos opuestos entre sí como en las lenguas eslavas, sino que todos los verbos — según el contexto- pueden tomar uno u otro aspecto; y por otro lado, todos los verbos, tanto los de significación perfectiva como los de significación imperfectiva, poseen formas verbales perfectivas y formas verbales imperfectivas. De aquí la necesidad de distinguir ambas nociones: la del «modo de acción» (...) y la del «aspecto» propiamente dicho».

Cuando se habla de aspecto desde el prisma de la expresión, se aducen flexiones, afijos, regularidades dentro de un paradigma verbal como argumentos que justifican el carácter gramatical de aquella categoría. Por contra, la entidad no-gramatical de la Aktionsart viene dada por la ausencia de terminaciones y flexiones sistemáticas en un paradigma, lo que hace concluir su carácter léxico.

El recurso a los procedimientos concretos y mecánicos de expresión para diferenciar «aspecto»y «Aktionsart» y para adscribir -tomando aquellos mecanismos como criterio- sólo el aspecto a la Gramática mientras se le niega importancia en este ámbito a la Aktionsart, tiene su origen en la perspectiva sesgada, parcial y de servidumbre que se ha adoptado tomando como patrón lo que tradicionalmente se ha entendido como aspecto en las lenguas eslavas. En efecto, dado que en lenguas como el ruso se consigue la oposición «imperfectivo» vs. «perfectivo» mediante afijos de modo regular en cada verbo (cfr. citat' (imperfectivo) / procitat' (perfectivo), que corresponde al verbo «leer»; igrat' (imperfectivo) / sygrat' (perfectivo), correspondiendo a «jugar»; pisat' (imperfectivo) / napisat' (perfectivo), que remiten al verbo «escribir», etc.), de ahí que el mismo requisito de mecanismo afijal de expresión quiera imponerse a otras lenguas para poder hablar de aspecto.

Esta manera de proceder resulta, no obstante, inadecuada por dos razones fundamentales. De una parte, porque no permite respetar el principio de peculiaridad y autonomía de cada sistema lingüístico al subordinar las estructuras de lenguas variadas a lo que son formalizaciones específicas de una(s) lengua(s);o lo que es lo mismo, al limitar —e incluso impedir - que cada lengua establezca y seleccione los cortes de modo propio. De otra parte, porque arranca de la idea - a todas luces errada - de que el aspecto ha de identificarse y concebirse sobre

«El modo de acción es una categoría semántica que indica la manera en que se desarrolla una acción o dura un proceso expresado por el verbo. Es un fenómeno perteneciente al plano lexical o morfológico (puede realizarse por medio de afijos derivativos), y no gramático-flexional. EI aspecto se caracteriza por una regularidad que, prácticamente, se extiende a todos los verbos conjugables sea cual fuere su valor semántico» 
la interpretación que tal noción y categoría recibe en la tradición eslava; pero es que ni siquiera la lingüística eslava se ha visto libre de prejuicios a la hora de enfrentarse con los fundamentos de la noción.

Como ya diferentes autores han señalado, el recurso a los mecanismos concretos de expresión tomando como prototipo las lenguas eslavas para llegar a determinar la categoría gramatical aspecto en las lenguas conduce a graves inconsecuencias.

Sin entrar en razones históricas que de ningún modo permiten una relación estrecha entre lo que ocurre con el aspecto en las lenguas eslavas frente a otras lenguas ${ }^{7}$, se ha hecho ver que en realidad, ateniéndonos a los procedimientos sustanciales de expresión, las lenguas eslavas evidencian un aspecto derivativo antes que flexivo, lo que obliga a situar esta categoría en el nivel léxico o a medio camino entre el léxico y la gramática. Así lo ha notado Dahl $(1985,89)$ :

«the Slavic-type aspect categories are no proper 'inflectional categories' but rather 'derivational' or maybe even 'grammaticalized lexical categories'. The semantic differences that we have seen might then reflect the fact that the Slavic categories grammaticalize 'perfectivity: imperfectivity' on the lexical or derivational level rather than in inflectional morphology»

Y, de modo similar, se ha referido a ello Cohen $(1989,144)$ cuando afirma que el ruso

«oppose, pour l'expression des aspects (A et B), deux verbs distincts. Ceux-ci peuvent être liés génétiquement par un processus compositionnel et/ou drivationnel. Mais ils ne le sont pas toujours. Parfois les verbs complémentaires sont sans rapports formels. Parfois aussi, le verbe est isolé, soit qu'il se trouve dépourvu de valeur aspective, soit qu'il n'ait pas de correspondant opposé» (subrayado mío).

Se da, por tanto, la paradoja de que el sistema aspectual habitualmente tomado como estándar gramatical para valorar esta categoría en las lenguas, no parece responder a requisitos gramaticales sino más bien a cauces léxicos. Las inconsecuencias resultan de haberse limitado a la relativa regularidad de las expresiones afijales concretas, sin importar su carácter más o menos gramatical; de ahí partió el trasvase a otras lenguas: hay aspecto si los mecanismos afijales de expresión muestran cierta regularidad, aún hallándonos ante paradigmas flexivos (y no «lexemas» o paradigmas léxico-derivativos) ${ }^{8}$, y a costa de que las particiones nocionales - por los contenidos — no sean totalmente equivalentes.

Ctr. Brinton 1988, 1.3.3.; y, sobre todo, nota 19 al cap. 3 en donde la autora ofrece una panorámica histórica de los factores de innovación implicados en el aspecto de las lenguas eslavas.

* Denominaciones éstas utilizadas por, respectivamente, Dahl (1985) y Cohen (1989) para referir la situación en las lenguas eslavas. Así, Dahl $(1985,89)$ dice que

«the Slavic categories grammaticalize 'perfectivity: imperfectivity' on the lexical or derivational level rather than in inflectional morphology»; 
Lo que se obtiene, al final, manejando ese criterio excesivamente sustancialista ligado a la presencia de afijos en las lenguas eslavas aunque sin importar su carácter, es una visión del aspecto como categoría gramatical limitada al verbo en su vertiente de paradigma morfológico ${ }^{9}$. En absoluto se amplía su consideración desde el prisma sintagmático, ni tampoco se rompe con la tendencia particularista de aproximación ${ }^{10}$ que lo identifica por mecanismos afijales regulares. De manera que la diferencias entre aspecto y Aktionsart pasa siempre por criterios de expresión antes que por razones nocionales, criterios de expresión que se proyectan marcando fronteras específicas y particulares en las distintas lenguas.

Si bien se trata de individualizar el aspecto - como categoría gramaticalfrente a la Aktionsart — como categoría léxica- por razones de expresión, sin embargo el cauce no parece claramente delineado al producirse entrecruzamientos entre las lenguas, e incluso interpretaciones divergentes sobre unos mismos hechos. Se echa en falta una perspectiva unitaria y general que sitúe en sus justos términos - sin contradicciones ni paradojas - la diversidad de las lenguas a este respecto ${ }^{14}$; pero ese acercamiento no ser factible por la vía de los afijos y terminaciones que no son sino manifestaciones sustanciales variadas.

\subsection{Valoración de los criterios de distinción}

Desde el prisma nocional puede pretenderse el enfoque unitario y general dado que aspecto y Aktionsart se sitúan en una misma órbita conceptual. No obstante, el criterio nocional tiene escasa rentabilidad cuando se pretende diferenciar las dos categorías, que al final se distinguen sólo por la vía de la expresión.

y de ahí que se trate de «grammaticalized lexical categories» (ibidem).

Cohen $(1989,144)$ habla de «deux verbs distincts» en el caso de las oposiciones aspectuales en las lenguas eslavas, frente a las oposiciones « à l'intérieur du même verbe» en las lenguas semíticas.

9 Lo que no es exclusivo del aspecto sino de las demás categorías llamadas «morfológicas» presentes en las palabras (género, número, tiempo, etc.), categorías siempre identificadas sobre la base de la segmentación de afijos y justificadas por la oposición paradigmática entre las funciones que presentan.

10 Brinton $(1988,19)$ destaca que

«there has been an emphasis on how particular forms are used in individual languages, and no clear idea of the basic underlying categories of aspect has emerged»

"Cohen (1989) entiende que la cuestión del aspecto pide una aproximación sustentada en el principio de unidad y diversidad de las lenguas. En concreto, respecto a la variedad señala que

«l'organisation du systême peut différer aussi bien dans sa réalisation morphologique que dans le détail des fonctionnements. Rappelons brièvement ici un trait fondamental qui différencie la forme de systéme qui prévaut en slave de celle qui prêvaut en semitique (...)

Du point du vue formel, le premier oppose, pour l'expression des aspects ( $A$ et $B$ ), deux verbs distincts. Ceux-ci peuvent être liés génétiquement par un processus compositionnel et/ou drivationnel. Mais ils ne le sont pas toujours. Parfois les verbes complémentaires sont sans rapports formels. Parfois aussi, le verbe est isolé, soit qu'il se trouve dépourvu de valeur aspective, soiy qu'il n'ait pas de correspondant opposé.

Le second systéme instaure l'oppositions l'intérieur du même verbe- et de chaque verbe-par un procédé d'alternance morphologique réguliére» (pg. 144) 
En efecto, la base de la «objetividad» vs. la «subjetividad» en la que quiere apoyarse la distinción «Aktionsart» vs. «aspecto» hace aguas por todas partes ${ }^{12}$ hasta Ilegar a interpretarse «lo objetivo» como «lo léxico» y «lo subjetivo» como «lo gramatical» y a perderse, por tanto, la aproximación nocional y con ella las ventajas de un acercamiento unitario a la cuestión.

Nocionalmente, pues, no parece que se disponga de argumentos y pruebas suficientes para sostener el enfrentamiento Aktionsart vs. aspecto. Por otra parte, el ámbito nocional es el único que permitiría la consideración unitaria y general de la pareja, ya que atendiendo a la expresión la realidad de las lenguas es muy variada y no cabe apoyar la distinción en principios generales que alcancen al carácter de los contenidos: se trataría, sin más, de la frontera entre procedimiento léxico y procedimiento afijal, variable entre las lenguas a la hora de expresar unos mismos contenidos.

Por el criterio de la expresión, y considerando «expresión» como equivalente a «procedimiento», se distingue sin dificultad en cada lengua el aspecto (expresión afijal, no léxica) y la Aktionsart (expresión léxica), pero está claro que las categorías no se identifican con los procedimientos sino que han de tenerse presentes los contenidos, los significados. Y es entonces cuando surgen los problemas respecto a los límites dado que unos mismos contenidos se expresarán léxicamente en unos casos y afijalmente en otros: ¿serán aspecto o Aktionsart?, ¿lo serán dependiendo de la lengua particular?, ¿se decide desde el patrón de las lenguas eslavas?

La cuestión del aspecto, y la de la distinción entre aspecto y Aktionsart -que nació para delimitar más ajustadamente aquella noción como categoría gramatical- necesitan revisarse y replantearse con miras a obtener una concepción rigurosa y bien determinada sobre sus fundamentos; concepción que ha de permitir una interpretación unitaria y autónoma de su carácter gramatical en las lenguas. Para lograr estos objetivos, se hace preciso en primer lugar abandonar el criterio de los mecanismos de expresión como pauta básica para identificar el aspecto frente a la Aktionsart; de otro modo el enfoque obligar a limitarse a cada lengua particular y no posibilitar la visión unitaria de los hechos lingüísticos (que se definen por ser más que procedimientos de expresión). Además, es imprescindible romper con el hábito tradicionalmente extendido de tomar como modelo lo que es el aspecto en las lenguas eslavas; si no, estamos abocados a una consideración de la categoría en relación de servidumbre con lo que ocurre en un patrón particular, lo que choca con el principio de autonomía de las

12 Cohen $(1989,34-35)$ se refiere a la ambigedad y relativismo de «lo objetivo» y «lo subjetivo», lo que impide que se conviertan en parámetros fiables para diferenciar «Aktionsart» y «aspecto». Concluye así que

«1l est évident par ces exemples que les notions d'objectivité et de subjectivité sont rapportes, dans les différentes définitions de l'aspect, des termes différents de ces définitions. L'ambigüité qui en résulte les rend peu éclairantes» $(1989,35)$. 
lenguas, y lo que puede conducir en muchos casos a distorsiones de los hechos linguísticos al ser valorados desde el prisma de otras estructuras. Finalmente, es de importancia crucial determinar - en paralelo con la debilidad atribuida a los mecanismos sustanciales de expresión - dónde radica el carácter gramatical de las unidades, de las categorías lingüísticas, con objeto de poder conceder el rango definido que les corresponda al aspecto y a la Aktionsart. Con toda seguridad, al plantearse la cuestión de los fundamentos gramaticales más allá de los procedimientos concretos de expresión, surgirá la necesidad de una perspectiva unitaria y general, así como la urgencia de atender no sólo a la paradigmática sino también a la sintagmática implicada por las nociones. Desclés $(1978,196)$ se ha referido a ello explícitamente:

«Nous pensons que pour décrire l'aspect grammatical, il est nécessaire d'associer non pas un type de marqueurs linguistiques une représentation conceptuelle mais de représenter les occurrences de ces marqueurs» ${ }^{13}$.

El primer paso significativo dado hacia el replanteamiento y la revisión del aspecto ha sido el que conduce a reconocer de manera explícita un único ámbito nocionalmente hablando. Desde el prisma nocional, el área es de la aspectualidad y no del aspecto y de la Aktionsart, de modo que cabe la consideración unitaria y general de los contenidos situados en aquella órbita.

Hay autores que se centran en la aspectualidad o en el aspecto -tomado genéricamente- y distinguen tipos y formalizaciones diversas en las lenguas. Así, para Lindstedt $(1985,58)$,

«Aspectuality is the semantic domain of aspect; it means reference to the situation class»,

mientras que el aspecto sería la vía gramatical de formalizar los «contenidos aspectuales»:

«Aspect is a grammatical category which classifies situations denoted by sentences into events, processes, states, and similar classes» (Lindstedt, $1985,57)$.

Como cabe suponer por la definición dada de aspecto, Lindstedt no hace equivalente «categoría gramatical» a «categoría flexiva», de manera que el aspecto (que es categoría gramatical) puede expresarse a través de procedimientos diversos (flexivos, léxicos, etc.). Con palabras de Lindstedt (1985, 153),

13 Con más detalle, para Desclès $(1978,198)$,

«Une CATEGORIE GRAMMATICALE est un système de correspondance entre $\left(1^{\circ}\right)$ des notions grammaticales (que représentent des valeurs) et $\left(2^{\prime}\right)$ des marqueurs morpho-syntaxiques repérables dans des textes dont des segments sont eux-mêmes catégorisés dans des classes linguistiques» 
«Aspect has been defined as a grammatical category, but not necessarily inflectional: if the members of an aspectual pair are different lexemes (...), aspect is a classificatory grammatical category, comparable to, say, the gender of nouns» (subrayado mío).

De este modo, el carácter gramatical del aspecto, su rango como categoría en el ámbito de la Gramática, se justifica no por los mecanismos concretos de expresión sino por factores de orden formal como su organización sistemática y opositiva en paradigmas:

«The grammaticality of aspect is shown by the strong tendency to form aspectual pairs, irrespective of whether the means of formation; hence aspect is at least a paradigmatic category, if not inflectional» (Lindstedt, 1985, 154).

En esta misma línea de reconocimiento de la aspectualidad desde la perspectiva nocional, algunos autores han establecido «aspectos» y modos de proyección de la aspectualidad; diferenciaciones todas ellas que en gran medida continúan dando vigencia al par «aspecto»/《Aktionsart». Así ocurre con el «aspecto inherente» y el «aspecto gramatical» de Comrie(1976); con el «carácter aspectual» y el «aspecto» de -entre otros- Seljakin (1984); con el «aspecto situacional» (situation-aspect) y el «aspecto de perspectiva» (viewpoint-aspect) de Smith (1983); o con la distinción de Brinton (1987) y (1988) en el ámbito nocional de la «aspectualidad» entre «Aktionsart» y «aspecto».

Como se ha dicho, el enfoque en todos estos casos es nocional, admitiéndose una única área semántica, la de la aspectualidad, que integraría clases y tipos diversos establecidos ya en su seno. Ello permite considerar que el «aspecto» y la «Aktionsart» comparten ámbito, y que en ese nivel semántico son -como Sasse $(1991,32)$ ha señalado «one and the same thing»; con otras palabras, esta aproximación parece facilitar el respeto de unidad en el orden semántico que, como atinadamente ha hecho notar García Hernández (1977, 70),

«abarca todo el plano del contenido, sea en expresión gramatical, sea en expresión lexemática» ${ }^{14}$.

14 B. García Hernández defiende la unicidad semántica del «aspecto» y la «Aktionsart», y remite tal distinción al nivel de los mecanismos de expresión:

«la distinción entre uno y otro («aspecto gramatical» y «aspecto léxico», M.F.P.) pertenece al plano de la expresión (...) y sólo afecta, indirectamente, al contenido en cuanto que cualquier unidad léxica permite la articulación gramatical en cualquiera de sus términos. Lo que es inadmisible es que hoy día se siga afirmando que la «diferencia entre modalidad de acción y aspecto radica en que la primera es de orden semántico y el segundo puramente flexional», como si el «orden semántico» no trascendiera el nivel léxico, cuando, en realidad, abarca todo el plano del contenido, sea en expresión gramatical, sea en expresión lexemática» (García Hernández, 1977, 70)

Si bien asocia la distinción con procedimientos de expresión, García Hernández no la maneja ya que habla siempre de aspecto y señala como

«error metodológico el separar terminantemente la expresión léxica del aspecto de su expresión gramatical» $(1977,66)$. 
Una vez establecida el área nocional de la aspectualidad, se proponen clases y tipos que aunque quieran hacerse descansar en criterios genéricos que trasciendan la particularidad de las lenguas, no obstante acaban justificándose desde los mecanismos concretos de expresión y equiparándose con los términos tradicionales de la distinción «Aktionsart» vs. «aspecto». Y es que - como ya he hecho notar- el recurso a la «objetividad» y a la «subjetividad» no parece suficientemente claro y riguroso como para conducir a delimitaciones y clasificaciones nítidamente trazadas, de modo que al final se resuelve por la vía de la expresión. Así sucede, por ejemplo, con los tipos de aspecto propuestos por Comrie, o con el par «Aktionsart» vs. «aspecto» manejado por Brinton. En efecto, Comrie (1976, 6-7) dice que

«In the present book we shall speak of semantic aspectual distinctions, such as that between perfective and imperfective meaning, irrespective of whether they are grammaticalised or lexicalised in individual languages»,

y también (pp. 8-9) que

«we have not placed any restriction on how semantic aspectual distinctions are to be grammaticalised in order to qualify as aspects, an indeed we shall not be placing any such additional restrictions, although many other writers on aspect have attempted to so»,

y aunque insiste (especialmente en el capítulo 5 de su libro) en que los mecanismos de expresión de los contenidos aspectuales en las lenguas interesan a la Lingüística descriptiva de cada una de esas lenguas antes que a la investigación del aspecto desde el prisma de la Linguiística general, sin embargo llega Comrie a identificar el carácter gramatical del aspecto por los procedimientos sustanciales de expresión, de la misma manera que llega a aislar el «aspecto inherente» por mecanismos léxicos ${ }^{15}$. Tal diferenciación entre «aspecto gramatical» $\mathrm{y}$ «aspecto inherente», sustentada en criterios de expresión, debiera limitar su operatividad al terreno de la Lingüística descriptiva, pero Comrie le confiere carácter general desde el momento en que reconoce contenidos aspectuales que son «aspecto inherente»y contenidos aspectuales que son «aspecto gramatical». Se eleva, así, al nivel de tipología general de la aspectualidad la clase reconocida como aspecto gramatical con los contenidos reflejados en el siguiente cuadro propuesto por Comrie $(1976,25)$

15 Incluso hace explícita la equiparación entre «aspecto inherente» $\mathrm{y}$ «Aktionsart» $\mathrm{y}$ «aspecto gramatical» $y$ «aspecto» cuando dice (Comrie, 1976, nota 4, pp.6-7)

«aktionsart represents lexicalisation of the distinctions, irrespective of how these distinctions are lexicalised; this use of aktionsart is similar to the notion of inherent meaning (related to the general semantic definition of aspect given above) discussed in chapter $2 »$.

El recurso a los mecanismos flexivos o perifrásticos para hablar de aspecto gramatical es criticado (aunque con una finalidad distinta a la que a mí me guía) por Brinton (1988, nota 20 cap. 1), quien reprocha a Comrie el acercamiento excesivamente formal. 
«Table I. Classification of aspectual oppositions

Perfective Imperfective

Habitual Continuous

Nonprogressive Progressive»;

y la clase catalogada como aspecto inherente, que recoge los contenidos «puntual»vs. «durativo», «télico» vs. «atélico», «estado» vs. «dinámico» (cfr. Comrie, 1976, cap. 2). De manera que se llega así a una clasificación de los contenidos aspectuales - que son generales - en gramaticales e inherentes, a partir de sus modos de expresión —que son particulares en las lenguas-, sin tener presente que los procedimientos de expresión sustancial no sirven como criterio para marcar fronteras entre contenidos generales; y menos si hay entrecruces y mezclas en los mecanismos y la adscripción a la clase, como sucede con - por ejemplo- el par «télico»vs. «atélico», que se trata como contenido aspectual inherente siendo su vía de expresión más bien sintáctica que léxica, a través de «situaciones» ${ }^{16}$ que incluyen

«the verb together with its arguments (subject and objects)»(Comrie, $1976,45)$.

Mientras Comrie (1976) distingue clases de «contenidos aspectuales» en el ámbito de la aspectualidad, Brinton (1988) reconoce, asimismo en el área de la aspectualidad, el «aspecto» frente a la «Aktionsart», e insiste en que tal distinción resulta crucial para una interpretación adecuada de la aspectualidad ${ }^{17}$. El criterio que esta autora quiere manejar para sustentar la pareja es de carácter

16 Lo cierto es que la necesidad de atender a «situaciones» antes que a «verbos» únicamente se hace patente también en las demás distinciones de aspecto inherente, como el mismo Comrie manifiesta al decir (1976, nota 1, pg. 42)

«Strictly speaking, it is the situation, rather than the verb, that is punctual»,

o al hablar de State and dynamic situations (pg. 48). Siendo así, un mismo verbo, dependiendo de la «situación», puede ser télico o atélico, puntual o durativo, estativo o dinámico.

También para diferenciar imperfectivo de perfectivo, habitual de continuo, etc. recurre Comrie a la situación, a la combinatoria (cfr. 1976, cap. 1). Es evidente que la expresión no es un mecanismo diferenciador de contenidos aspectuales.

17 Con palabras de Brinton (1988, 3),

«This work will argue that the distinction between aspect and aktionsart is crucial, and that the aspectual interpretation of a sentence depends on an interaction between these two categories»; esta misma opinión vuelve a recogerse en el capítulo 6 dedicado a conclusiones, donde dice (pg. 235)

«The meaning and function of the aspectual forms is best understood if a clear distinction is drawn between inherent temporal features of dynamicity, durativity, and telicity of a situation (its 'aktionsart') and the presentation of the situation as complete, incomplete, or partial (the 'aspect' under which it is viewed)» 
nocional: recurre así a las pautas de «objetividad» y «carácter de la situación» como base de la Aktionsart, y a las de «subjetividad» $\mathrm{y}$ «punto de vista» como fundamento del aspecto; y resalta además explícitamente — después de criticar la debilidad de las aproximaciones centradas en la expresión (cfr. 1.3, y especialmente 1.3.3.)- que

«Aspect categories should be established not on the basis of formal markers existing in a certain language, but on the basis of (universal) notional distinctions. Aktionsart categories must be defined precisely in terms of relevant features» (Brinton, 1988, 52).

Ciertamente, el enfoque nocional desde la aspectualidad y la valoración negativa de un prisma excesivamente formal en el estudio del aspecto, facilitan a Brinton un acercamiento al tema por cauces de generalidad y rigor que no se habían dado en estudios previos. Por lo de pronto, hay variedad de mecanismos de expresión tanto en la Aktionsart como en el aspecto ${ }^{18}$, rompiéndose la equiparación «Aktionsart = expresión léxica», «aspecto = expresión flexional». No cabe, por tanto, la remisión del aspecto en exclusiva al terreno de la Gramática como en ocasiones se había defendido arguyendo factores de expresión.

Por otra parte, la distinción ha de justificarse por razones que trasciendan las expresiones concretas. Como indicaba anteriormente, el criterio de Brinton pretende ser nocional («objetividad» vs. «subjetividad») y responder a «the basis of (universal) notional distinctions» (Brinton, 1988, 52); sin embargo, en ningún momento se hacen explícitas las bases de adscripción de unos contenidos al aspecto y de otros a la Aktionsart, resultando que - curiosamente- las clasificaciones coinciden en cierta medida con lo que se había propuesto en versiones tradicionales y poco rigurosas de la cuestión.

Así, hay ocasiones en las que da la impresión de que la distribución responde al carácter de «composicionalidad» y complejidad, que será propio de las categorías de Aktionsart ${ }^{19}$ antes que del aspecto. Composicionalidad ésta que se

18 El aspecto puede proyectarse por flexión, perífrasis, aspectualizadores, etc. (véase Brinton, 1988, cap. 2); y lo mismo sucede con la Aktionsart, que se expresa por mecanismos sintácticos, por adverbios, etc. (véanse capítulos 4 y 5 )

19 Esto explica que Brinton conciba la definición de los contenidos de Aktionsart «en términos de rasgos relevantes» (cfr. 1988, 52), y que proponga la siguiente matriz de rasgos para caracterizar aquellas categorías de Aktionsart $(1988,57)$

DINAMICITY DURATIVITY HOMOGENEITY TELICITY MULTIPLICITY

$\begin{array}{lll}\text { state } & - & + \\ \text { achievement } & + & - \\ \text { activity } & + & + \\ \text { accomplish } & & \\ \text { ment } & + & + \\ \text { series } & + & +\end{array}$


interpreta tanto en el sentido de la definición a base de rasgos como en el sentido de la combinación de procedimientos (mediante adverbios, funciones sintácticas, etc.) para alcanzar aquel significado.

En otras ocasiones, parece que la atribución de contenidos a cada una de las clases viene dada por el distinto rango que les corresponde ${ }^{20}$. En efecto, mientras los significados de aspecto se refieren a «the presentation of the situation as complete, incomplete, or partial» (Brinton, 1988, 235); los significados de Aktionsart refieren «inherent temporal features of dinamicity, durativity, and telicity of a situation» (ibidem). De manera que la selección de la situación parece primarse desde la Aktionsart; y sólo después se enfocaría y presentaría desde el aspecto. No obstante a nadie se le escapa que el carácter de la situación (la Aktionsart) y el enfoque (el aspecto) interaccionan sin que exista prioridad alguna en la génesis y el proceso del discurso ${ }^{21}$. Quizás sean razones metodológicas las que llevan a Brinton a defender con insistencia la separación entre las dos categorías. Con toda probabilidad, el hecho de que no quepa una ordenación

20 Detrás está, de nuevo, el criterio «objetividad vs. subjetividad», o lo que algunos como Bache (1982) -al que Brinton dedica la extensa nota 58 al capítulo $1^{\text {!? }}$ (véase pg. 257) - han denominado «características procesuales» de una situación frente a «foco situacional». De todos modos, Bache relativiza la distinción Aktionsart vs. aspecto en términos de «objetividad vs. subjetividad» llegando a hablar de «quasiobjetividad» y «quasisubjetividad»; con sus palabras (Bache, 1982, 70-71),

«Aktionsart concerns the procedural characteristics (i.e. the 'phasal structure', 'time extension' and 'manner of development') ascribed to any given situation referred to by a verb phrase whereas aspect reflects the situational focus with which a situation is represented. Sometimes the speaker/ writer has a 'subjective choice' between two ways of representing the situation (in cases of pure aspectual opposition), sometimes he MUST choose one or other way of representation (in cases where the aspects function in different ways in relation to tense and Aktionsart). This interpretation of the difference between aspect and Aktionsart is thus stated not in terms of 'subjectivity' versus 'objectivity' but rather in terms of what might be called 'quasi-subjetivity' and 'quasi-objetivity'».

$2 !$ Valgan como prueba algunos ejemplos de casos considerados por Comrie (1976). Así, al definir el progresivo como

«the combination of progressive meaning and nonstative meaning» $(1976,35)$

está incidiendo en el hecho de que la asociación implica un desarrollo simultáneo de aquellos conceptos: no es que se elija primero la situación dinámica, y después la perspectiva progresiva, sino que para lograr la situación progresiva es imprescindible dicha combinación. De otro modo, si se concede prioridad a uno de los componentes sometiendo el progresivo a situaciones dinámicas, o definiendo la estatividad en términos de incompatibilidad con la progresión, se llega a caracterizaciones circulares que Comrie trata de evitar (nota 4, pg. 35):

«The explanation at this point may seem completely circular: progresiveness is defined in terms of stativity, but is then taken as sufficient evidence for classifying a given verb as stative or nonstative, i.e. Portuguese ver 'see' can occur in the Progressive because it is nonstative, and it is nonstative because it can occur in the Progressive».

Véase también su modo de caracterizar el «aspecto ingresivo», con la intervención simultánea del perfectivo y la estatividad (pp. 19 y ss.); o el análisis del «aspecto puntual» (¡inherente!) que hay que valorar en relación con el «imperfectivo» para - a través de la iteración- considerarlo frente al «durativo» y reconocer el «semelfactivo».

En resumen, hay argumentos para defender tanto la prioridad de los contenidos «inherentes» sobre los «gramaticales», como para defender que de la elección del «aspecto gramatical» deriva el «aspecto inherente». 
jerárquica conjunta de todos los contenidos pertenecientes a la aspectualidad ha sido motivo para mantener la distinción entre Aktionsart y aspecto. Ahora bien, esto mismo sucede en otros ámbitos como el del «modo» ${ }^{22}$, sin que se establezcan fronteras entre clases y zonas dentro de aquella categoría unitaria.

El peso de los argumentos metodológicos hay que valorarlo, en mi opinión, en su justa medida. En el caso concreto que nos ocupa, continuar con el par «Aktionsart» - «aspecto» entraña riesgos e inconvenientes que aconsejan su abandono.

En primer lugar, está la debilidad del criterio conceptual (no metodológico) en que quiere apoyarse. Ya se ha señalado en diferentes ocasiones y por distintos autores la borrosidad entre la base «objetiva» y la «subjetiva». Además, y en consonancia con esta endeblez del fundamento, conviene preguntarse si todas las lenguas tamizan determinados contenidos conceptuales en el mismo sentido de atribuirlos al «carácter de la acción» y al «punto de vista»; y es que no parece descabellado pensar en que existan divergencias entre las lenguas a la hora de seleccionar y distribuir los contenidos aspectuales en categorías.

En segundo lugar, está el peligro de seguir con la identificación del aspecto y de la Aktionsart a través de los procedimientos sustanciales de expresión, riesgo éste que L. Brinton se cuida de evitar cuando admite procedimientos variados de expresión en los dos casos, pero que sin embargo existe desde el momento en que continúa vigente la nomenclatura y hay coincidencias fuertes con la propuesta tradicional en la clasificación de las categorías.

Finalmente, está el hecho de que las vías metodológicas de análisis deben ligarse a una determinada concepción de la aspectualidad, del aspecto y de la Aktionsart, con objeto de que los cauces descriptivos resulten perfilados, sin contradicciones, y definidos hacia algún sentido en todos los casos. No se trata sólo de dar cuenta —como es el propósito de Brinton $(1988,235)$ - del «meaning and function of the aspectual forms» a través de la distinción necesaria, según la autora, para la consecución de aquellos fines-entre categorías de Aktionsart y de aspecto, sino que es imprescindible plantearse dónde radica el valor gramatical del aspecto en las lenguas: se hace precisa, pues, una concepción general sobre la relevancia y el papel de la categoría. Con otras palabras, para lograr «the aspectual interpretation of a sentence» (Brinton, 1988, 3), que depende — según la autora — de la «interacción» de las categorías de aspecto y Aktionsart, hay que evaluar la incidencia estructural de las propiedades aspectuales en la lengua, lo que obliga a una visión general del estatus del aspecto en los sistemas lingüísticos.

22 En el modo se reconocen dos parámetros que organizan, respectivamente, la oposición «indicativo» vs. «subjuntivo» y las oposiciones «irrealidad» vs. «no irrealidad» y «probabilidad» vs. «no probabilidad» (cfr. Veiga, 1991, cap. II), pero siempre se remiten a una sola categoría, la de modo. 
Sólo arrancando de esa concepción podrán los análisis y las descripciones conducir a resultados interesantes sobre la incidencia del aspecto en el entramado lingüístico; de otro modo, se daría cuenta, sin más, de los contenidos aspectuales implicados en las expresiones.

Pues bien, desde ese prisma conceptual que ha de otorgar un estatus al aspecto en la estructura de las lenguas, la distinción «Aktionsart vs. aspecto» por razones metodológicas no parece sostenible, ya que el análisis y la descripción se desarrollan contando sobre todo con las implicaciones de los contenidos, y con su posible pertenencia a una clase o rango.

De cualquier modo, hay que admitir un avance importante en estas nuevas propuestas en el sentido de que han comenzado a romper con la visión tradicional del aspecto que limitaba la expresión a procedimientos flexivos. Ahora se ha dado cabida a una gama de expresiones variadas: la calidad para hablar de aspecto está en otros factores y no sólo en la expresión flexiva.

Hay que atribuir al acercamiento nocional la ventaja de la unicidad en el tema del aspecto y de la Aktionsart y también la relevancia de su planteamiento abierto respecto a las posibilidades de expresión aspectual, rompiendo con las estrecheces tradicionales de los procedimientos flexivos.

El segundo paso importante y yo diría que crucial para hallarnos con un enfoque rico en esta cuestión es el que conduce a interpretar los significados aspectuales como producto no exclusivamente limitado al paradigma verbal. De ello resulta la concepción sintagmática y composicional de la noción, así como la ruptura definitiva con la asociación tradicional del aspecto a expresiones afijales y flexivas. Al dar ese paso, se llega a una situación —que según Bosque $(1990,177)$ empieza a vislumbrarse-de

«cierto acuerdo en el hecho de que la gramática de esas nociones (aspecto y Aktionsart, M.F.P.) no es tan independiente como dan a entender sus respectivas definiciones».

\section{El aspecto y la Aktionsart desde una perspectiva general y unitaria}

La situación en la que se encontraban hace sólo unos años las investigaciones en torno al aspecto y alrededor de la distinción aspecto vs. Aktionsart obliga - como he puesto en evidencia- a replantearse numerosas cuestiones con el fin de alcanzar una visión de la categoría que responda a su relevancia real en las lenguas.

Así, se ha roto con la tendencia a considerar el aspecto desde lo que se interpreta como patrón en las lenguas eslavas, y a partir de su expresión afijal. De manera que, por una parte, se reconoce que las lenguas eslavas no son modelo de «categorías aspectuales» en el sentido de «categorías flexivas», tal y como manifiesta —entre otros (cfr. también Cohen, 1989, 38 y ss.) — Dahl $(1985,89)$ : 
«the Slavic-type aspect categories are no proper 'inflectional categories' but rather 'derivational' or maybe even 'grammaticalized lexical categories'. The semantic differences that we have seen might then reflect the fact that the Slavic categories grammaticalize 'perfectivity:imperfectivity' on the lexical or derivational level rather than in inflectional morphology».

Por otra parte, comienzan a contemplarse estudios sobre el aspecto en dichas lenguas que no limitan la presencia de la categoría a expresiones afijales, como es el caso del ya clásico Forsyth $(1970)^{23}$, circunstancia ésta que pone de manifiesto la necesidad de revisar el valor de la categoría incluso en aquellas lenguas que se han tomado como patrón.

Al tiempo que se amplía la consideración del aspecto en lo relativo a posibilidades de expresión y sin limitarlo a lo que pueda ser su papel en las lenguas eslavas, la distinción aspecto vs. Aktionsart-que se sostenía en criterios de expresión - empieza a desdibujarse y ha de reinterpretarse si se quiere mantenerla. De este modo, el campo de referencia nocionalmente hablando es el de la aspectualidad: los significados aspectuales se agrupan unitariamente en un ámbito conceptual, sin que sea posible establecer una frontera entre los «significados aspectuales léxicos»y los «significados aspectuales gramaticales» por motivos formales. De ahí que se recurra a pautas nocionales como la «objetividad» y la «subjetividad» para marcar en términos conceptuales el límite entre Aktionsart y aspecto.

\subsection{El carácter «composicional» del aspecto y la concepción sintagmática de la categoría}

Una vez que se ha superado el nivel de la expresión sustancial y se ha optado por una aproximación a la categoría a través del prisma nocional, se sientan las bases para una consideración del aspecto desde una perspectiva general que no ciñe su presencia al verbo sin más, sino que alcanza a la combinatoria y a la variedad sintagmática de los verbos en las diversas estructuras. De manera que se llega a defender el carácter «composicional» del aspecto, así como la impor-

23 Forsyth atiende a la situación de los verbos según pautas de sistematicidad para clasificarlos por el aspecto. De este modo, reconoce $(1970,46-56)$ los cinco tipos siguientes:

1) Perfectivos desemparejados (ruxnut, 'colapsar').

2) Pares en los que el perfectivo expresa «an instantaneous effect of 'leap' into a new state»; mientras el imperfectivo sólo se utiliza para la habitualidad (naxodit'(imp.)/najti (perf.), 'to find').

3) Pares en los que el perfectivo expresa una transición a un nuevo estado (télico); mientras el imperfectivo indica «the tendency towards, and graducal approach to, the critical point at which the action takes place» (atélico) (umirat' (imp.)/umeret' (perf.), 'to die').

4) Pares en los que el imperfectivo denota un proceso que «represents in itself the gradual achievement of the result» (atélico); frente al perfectivo, que expresa que el resultado se ha alcanzado completamente (télico) (pisat' (imp.)/napisat' (perf.).

5) Imperfectivos desemparejados, que expresan o bien varios estados, o bien varias actividades que no tienen por qué implicar alguna conclusión. 
tancia del contexto para determinarlo; y se llega, además, a reconocer que las nociones aspectuales no son exclusivas de aquella clase de palabra sino que pueden justificarse en estructuras con adjetivos y sustantivos ${ }^{24}$.

Si bien la calidad composicional (no siempre bien entendida) del aspecto se había resaltado en múltiples trabajos que marcaron un hito en el tratamiento de la categoría ${ }^{25}$, la relevancia del contexto - y con ella la consideración sintagmática del aspecto - no se hizo notar en la medida precisa que, no obstante, se había vislumbrado en la tradición linguística francesa. Gosselin, François et alii (1991) remiten a F. Brunot el principio de necesidad de atender a las predicaciones (antes que a los verbos) para obtener propiedades aspectuales; con sus palabras $(1991,34)$,

«Depuis F. BRUNOT, les types de procès n'ont donc plus été étudiès pour eux-mêmes dans les grammaires françaises (...) le caractère perfectif (borné) ou imperfectif (non-borné) du procès décrit ne peut pas toujours étre immédiatement déduit du verbe seul, indpendamment de son contexte».

Este modo de acercarse al aspecto por la vía sintagmática, incidiendo en la pertinencia del contexto y sin ceñir las propiedades aspectuales al verbo en exclusiva, ha sido el definitorio de la lingüística francesa, que constituye una excepción en este sentido por su peculiaridad en el interés mostrado en cuestiones aspectuales ${ }^{26}$. El problema fundamental que se plantea es el de determinar los valores aspectuales en el seno de estructuras, lo que evidencia que no cabe atribuir a un verbo una única carga aspectual sino que hay que contemplar sus diferentes proyecciones en diversas combinatorias; de esta manera, llega a formularse una de las preguntas básicas para interpretar adecuadamente la composicionalidad del aspecto y para alcanzar la concepción precisa y determinada sobre su rango en las lenguas ¿los contenidos aspectuales se manifiestan o por el contrario se logran en las estructuras sintácticas? ¿tales contenidos hay que situarlos en la potencialidad de los verbos, o bien hay que derivarlos de diversos mecanismos de combinatoria? El planteamiento de C. Fuchs $(1991,11)$ es como sigue:

24 Como botones de muestra, véanse los trabajos de Bosque (1990) y Rijkhoof (1991).

25 Como más relevantes se destacan: Vendler (1967), Verkuyl (1972), Mourelatos (1978) y Platzack (1979).

36 Gosselin et alii (1991) señalan que las investigaciones desarrolladas sobre el aspecto en el seno de la linguística francesa responden a móviles y objetivos muy diferentes a los que caracterizan los trabajos en otros entornos. Con sus palabras $(1991,75)$,

«Toutefois la linguistique franaise ne refléte pas exactement l'évolution des recherches dans ce domaine à l'étranger. En effet dans le domaine slave et germanique par exemple on observe une succession ininterrompue de travaux sur l'interprétation aspectuelle de régularités dérivationnelles et sur l'interférence entre le mode d'action et l'aspect» 
«les types de procès se calculent au sein des énoncés, grâce des règles prenant en compte non seulement les propiétés des unités lexicales mais aussi l'ensemble des indices prédicatifs et énonciatifs jugés pertinents. A ce compte, l'analyse se heurte un apparent paradoxe: d'une part les lexèmes sont intrinsquement chargés de valeurs ou, au moins, de potentialités sémantiques spécifiques, mais d'autre part le contexte d'emploi de ces lexèmes contribue lui aussi la construction de valeurs; dès lors, comment se situer dialectiquement entre le «tout dans les mots» et le «tout dans le contexte»?».

La cuestión - como decía - es fundamental, ya que si se defiende que los significados aspectuales se consiguen mediante la intervención de diversos procedimientos - y de ahí su «composicionalidad»-, no se supera el estadio de descripción de aquellos contenidos a través de los rasgos y factores de composición, faltando una concepción sobre el estatuto del aspecto en las lenguas. Además, se corre el riesgo de equiparar la Aktionsart, la combinatoria sintagmática y el mismo aspecto (gramatical, morfológico) con uno de los mecanismos de expresión, o con uno de los factores de composición, de dichos $\operatorname{contenidos}^{27}$. Dicho brevemente, se trata no sólo de dar cuenta de los significados aspectuales a través de los rasgos de composición implicados, sino sobre todo de sustentar la categoría que engloba los contenidos por su rango e incidencia en las lenguas ¿pertenece al léxico o a la gramática?, ¿por qué?

Por el contrario, si se entiende el carácter composicional del aspecto en un sentido más estricto y se opta por la idea de que los significados aspectuales potenciales se proyectan y manifiestan de diversa manera en diferentes lenguas y a través de mecanismos de expresión variados, entonces será posible plantear la relevancia de aquellos significados en las lenguas al margen de la descripción concreta en cada caso. De este modo, se admite la carga aspectual potencial en cada verbo y de ello resultan sus posibilidades de combinatoria en las diversas estructuras. Así pues, los contenidos aspectuales se manifiestan, se proyectan, antes que se logran o «se componen» en las distribuciones concretas. Según Seljakin $(1984,51)$,

«the particular meanings of the aspects are not created by the context, as is assumed lately by some linguists, but are revealed in the context as variants of contrasting general meanings which are established through a generalization of the particular meanings and their contrast»

\section{Así, Brinton $(1988,54)$ llega a decir}

«whereas iterative is a compositional meaning (resulting from progressive/contiuative aspect and punctual aktionsart) or an inherent aktionsart meaning (e.g. chuckle, wiggle, hammer, ...), habitual is a basic aspect meaning» (subrayado mío).

Evidentemente, estamos ante modos (entre otros varios) de proyectarse esos aspectos; en consecuencia, no se trata de rasgos definitorios sino de únicamente identificadores del aspecto iterativo y del aspecto habitual. 
Como he sugerido a lo largo del trabajo, el paso crucial de todos cuantos se han dado en la reconsideración y el planteamiento ajustado del aspecto —así como de la distinción aspecto vs. Aktionsart- hay que situarlo en la aproximación sintagmática que amplía la visión de la categoría. Se rompe así con la tendencia tradicional de ligar el aspecto a mecanismos sustanciales de expresión verbal en lenguas particulares; y ello porque se defiende una perspectiva nocional y semántica que responde a la funcionalidad real del aspecto en las lenguas. El resultado es un enfoque de la categoría desde la órbita de la Linguíistica general, lo que conduce a la necesidad de precisar el papel del aspecto en las lenguas, razón por la que hay que partir de una concepción definida sobre su estatus, enjuiciando las bases en las que quiere asentarse la distinción aspecto vs. Aktionsart.

Teniendo en cuenta según lo expuesto los sentidos de las diferentes aportaciones en el tema del aspecto y de la pareja aspecto vs. Aktionsart, defiendo la oportunidad de un enfoque de Lingüística general así como una concepción formal (no sustancial) sobre el rango de la categoría. Sobre tales bases no cabe seguir manteniendo aquella dicotomía: objetivamente sólo se justifica el aspecto.

Desde la perspectiva de la Lingüística general —que abarca todas las lenguas - la aproximación no puede ser sino nocional, de manera que el ámbito conceptual del aspecto y la Aktionsart es uno y el mismo. H.J. Sasse (1991) que se ocupa de la cuestión aduciendo evidencia tipológica afirma que desde un punto de vista cognitivo aspecto y Aktionsart son «one and the same thing».

Los criterios de «subjetividad» o «perspectiva» frente a «objetividad»o «carácter inherente» utilizados por algunos autores para reconocer la pareja en el ámbito nocional resultan endebles — como ya he señalado (véase apdo 1.1.; y nota 5) - , hasta el punto de conducir en buena parte de los casos (por ejemplo en Comrie, 1976) a pautas de gramaticalización y lexicalización para sustentar la distinción. $Y$ es que las lenguas divergen en el desarrollo de esos procesos aun cuando partan de idénticas nociones; y de ahí que no sea posible elevar a un nivel general lo que sólo es propio de una(s) lengua(s) que lexicaliza(n) y gramaticaliza(n) en un determinado sentido. Por consiguiente, y tal y como considera Sasse $(1991,43)$,

«It is clear that there are conceptual types of states of affairs which are universal, but not universally lexicalized. Moreover it is clear that there is a universal tendency to systematically express the conceptual distinction of situation and situation change, at least for certain types of states of affairs».

No cabe, por tanto, mantener la dicotomía en términos de Lingüística general; ni siquiera por razones metodológicas - que guían la organización jerárquica y sistemática de los contenidos- parece aconsejable seguir con la 
distinción (véase apdo. 1.2. $)^{28}$, dado que ello interfiere en el alcance de una concepción global sobre el estatus del aspecto.

En suma, desde el prisma general se reconocen contenidos aspectuales, significados relativos al desarrollo interno de los procesos, organizados en un solo y único ámbito nocional. Conviene, pues, abandonar la idea de distinción de tipos o grupos de significados, y con ella la etiqueta de «Aktionsart» ${ }^{20}$.

\subsection{EI rango gramatical del aspecto en las lenguas}

Una vez situados los contenidos aspectuales en ese nivel general, es necesario dar cabida a sus posibilidades de proyección formal en las lenguas particulares, de manera que por las implicaciones sintácticas de dichos contenidos se llegue a una concepción rigurosa del rango gramatical que corresponde al aspecto.

No se trata así de comprobar los procedimientos de expresión (afijal, perifrástica, léxica, etc.) de los significados aspectuales, sino de integrar el estatus gramatical de la categoría aspecto partiendo de su repercusión en las estructuras sintácticas. De modo que las nociones aspectuales se formalizarán en las lenguas dando lugar a la categoría gramatical aspecto en aquellos casos en los que los significados permitan, faciliten o impidan combinatorias y distribuciones, y ello independientemente de que el cauce material de expresión sea un afijo, un verbo, una perífrasis o un sintagma más complejo. Quiere esto decir que aunque los contenidos aspectuales sean «universales posibles» no todas las lenguas tienen por qué formalizar el aspecto (gramatical), ni tampoco tienen que hacerlo sobre significados aspectuales idénticos. Con palabras de Coseriu $(1978,14)$,

«une langue peut ne pas avoir d'aspect grammatical; cela, même si elle exprime parfois des contenus de type aspectuel dans son lexique ou bien au moyen d'autres catégories de la grammaire».

En relación con el valor sintagmático de la categoría está su carácter funcional y sistemático como causa o consecuencia de su relevancia gramatical, independientemente de los contenidos formalizados como aspecto y al margen

28 Efectivamente, hay autores como Sasse $(1991,32)$ que llegan a afirmar explícitamente que «It is methodologically problematic to define aktionsart as a universal category»

29) Sasse $(1991,44)$ se muestra también partidario de prescindir de aquella denominación: «I therefore propose to abandon the term aktionsart, even for those cases where it would seem most appropriate, namely languages of the «interactional» type with clear derivational distinctions (such as those found in Slavic). Aspectuality is always a matter of the correlation of lexical semantics and TAM categories, and can be ordered along a continuum from zero lexical and maximal grammatical distinctions to maximal lexical and zero grammatical distinctions» 
de su alcance y peso en la totalidad de las unidades gramaticales ${ }^{30}$. El valor, la funcionalidad gramatical, justifican la consideración del aspecto como categoría en las lenguas, dado que, recogiendo palabras de Coseriu $(1978,17)$,

«Une catégorie existe dans le systéme grammatical d'une langue si elle y fonctionne en tant que catégorie autonome, c'est-à-dire, si elle y est représentée par des oppositions spécifiques et non réductibles d'autres catégories. Et il en est de même en ce qui concerne les dimensions d'une catégorie quelconque et les contenus («signifiés») qu'elles déterminent»

En síntesis, el rango gramatical atribuido al aspecto desde el enfoque de Lingística general adoptado descansa en su proyección sintagmática, en sus repercusiones en la combinatoria sintáctica. Para evidenciar y justificar la presencia de valores aspectuales gramaticales se recurre al contexto, a la constitución de la estructura sintáctica, aunque sin perder de vista que se trata de resultados de implicaciones provocadas por valores aspectuales, antes que de rasgos y propiedades que «componen» el aspecto. Con otras palabras, el contexto, las situaciones sintagmáticas son cauces que proporcionan indicios, marcas, de la presencia objetiva de aspecto gramatical. No es de extrañar que para evitar malentendidos, diversos estudiosos del tema en el marco de la lingística francesa insistan en que no deben confundirse los resultados con los valores que los producen (cfr. Franckel \& Paillard, 1991, 114 y ss.); y que lleguen a considerar los peligros de una caracterización «composicional» a base de rasgos (que son más bien «productos»), frente a las ventajas de una caracterización por «valores» básicos (cfr. Fuchs, 1991, 15 y ss.; y tambin Franckel \& Paillard, 1991) ${ }^{3 !}$.

Las estructuras sintácticas - permitiendo o rechazando determinadas configuraciones- son, por consiguiente, cauce para lograr la identificación objetiva (aunque no la caracterización) de aspectos; y en este sentido resultan fundamen-

30) Hay que contar con que las oposiciones aspectuales no abarcan todas ellas en el mismo grado y en todas las circunstancias a los paradigmas de las unidades gramaticales. Como señala Coseriu $(1978,17)$,

«dans un système linguistique donné, les dimensions aspectuelles (...) puissent être permanentes ou «regulières» (c'est-à-dire qu'elles s'appliquent en principe à tous les verbes et, pour chaque verbe, dans tous les cas fonctionnellement analogues) ou qu'au contraire elles ne présentent qu'une réalisation limitée ou sporadique».

Este hecho es un buen motivo para plantearse la necesidad de estudiar el aspecto desde una perspectiva sintagmática.

3 En concreto, Franckel \& Paillard (1991) parten de lo que ellos llaman «configuraciones de base» en las que intervienen nociones como «discreto», «denso», «compacto»; y desde aquellas configuraciones - y por la vía metodológica que defiende las gradaciones y los continua- llegan a las diversas posibilidades de «valores» que cabe atribuir a las unidades según la relevancia de tales propiedades en los variados casos de combinatoria. De ahí que insistan en que

«dégager ce que l'on va appeler le ou les sens d'un mot revient à investir celui-ci de propiétés qui dépendent nécessairement d'une combinatoire déterminée» (Franckel \& Paillard, 1991, 104). 
tales a la hora de hacer patente que el peso - por su incidencia en la combinatoriade los contenidos aspectuales «objetivos» no es distinto del que corresponde a los contenidos aspectuales «subjetivos».

Así pues, moviéndonos en el campo de la Linguística general y manejando el criterio de rango gramatical que he propuesto, no es posible defender la dicotomía aspecto vs. Aktionsart.

Son numerosos y muy variados en estos últimos años los trabajos relativos a la importancia del aspecto en la Sintaxis. Aunque mi objetivo no es en términos estrictos sopesar y sistematizar la relevancia sintáctica de la categoría, sí parece imprescindible contemplar aquellos trabajos con el fin de mostrar que resulta a todas luces inadecuado mantener la distinción aspecto vs. Aktionsart ya que las proyecciones sintácticas no la sustentan.

Platzack (1979) enuncia el apartado 5.2. de su libro en los términos The Choice Between Direct Objects and Prepositional Objects as a Formal Way to Indicate Bounded Processes and Unbounded Processes, y se ocupa de cómo

«A large group of Swedish verbs can be construted either with a direct object, or with a prepositional object. These constructions sometimes denote different aktionsarten» (1979, 131; subrayado mío).

Observa Platzack que la construcción con C.D. conduce a un contenido aspectual de telicidad («bounded») mientras que la construcción con objeto preposicional lleva a un contenido aspectual de atelicidad («unbounded») ${ }^{32}$.

La correlación entre «transitividad» y aspecto fue resaltada de manera especial en un sentido teórico específico por Hopper \& Thompson (1980); y ha sido aprovechada en el análisis y descripción de lenguas particulares. En un trabajo reciente, T. Moure (1991) ha evidenciado el papel de los contenidos aspectuales 'télico' y 'atélico' en la configuración de determinadas estructuras sintácticas en español, así como la vinculación estrecha de aquellos contenidos con otras propiedades gramaticales como la determinación, la diátesis, etc. (cfr. 1991,363 y ss.).

32. Los ejemplos que maneja Platzack para evidenciar este hecho son los siguientes:

«(5.14) a Han byggde ett hus 'He built a house'

Han skrev ett brev 'He wrote a letter'

Han at ett pple 'He ate an apple'

Han sydde en kappa 'He sewed a coat'

b Han byggde pa ett hus (lit)'He built on a house'

Han skrev pa ett brev (lit)'He wrote on a letter'

Han at pa ett pple (lit)'He ate on an apple'

Han sydde pa en kappa (lit)'He sewed on a coat'

In these examples, the choice of a direct object gives us sentences referring to bounded processes, whereas the choice of a prepositional object gives us sentences referring to unbounded processes» $(1979,131-132)$. 
En esta misma dirección, Bosque (1990), después de referirse a la necesidad de

«articular un procedimiento formal explícito para lograr que la sintaxis y el léxico se repartan la tarea de explicar los efectos sintácticos que desde hace casi un cuarto de siglo se vienen atribuyendo a la naturaleza «durativa» o «puntual», «limitada» 0 «no limitada» de estos predicados« $(1990,181)$,

se ocupa de las peculiaridades sintagmáticas de algunos adjetivos, participios y adverbios que contienen cierta carga aspectual, peculiaridades que marcan no sólo diferencias de aspecto sino que sirven además para explicar fronteras entre las clases de palabras ${ }^{33}$.

También para otras lenguas se ha puesto de manifiesto la repercusión del aspecto en la Sintaxis, y así García Hernández $(1977,73)$ en su trabajo sobre el aspecto en latín afirma que

«la clase aspectual de un lexema influye directamente en la selección de su régimen preposicional u oracional».

Por su parte, Torrego (1988) incide en las restricciones que el aspecto impone para seleccionar en latín constituyentes sintácticos de duración. Heinmki (1984) considera, para el finés, el vínculo entre aspecto y caso y hace notar que el objeto - según sus propiedades- es índice de distinciones aspectuales, lo que le lleva a reconocer el aspecto gramatical en dicha lengua aun cuando falten marcas morfológicas en los verbos.

Algunos autores han llevado la presencia del aspecto hasta incluso los nombres identificando en este caso la carga aspectual con lo que habitualmente se entiende por 'determinación' y 'cuantificación'. Así se proponen nombres (o frases nominales) télicos («bounded») y nombres (o frases nominales) atélicos («unbounded»). Shi $(1990,53)$ diferencia esos dos tipos de la manera siguiente:

«one can say that the head of an NP names the entity, while the determiner or quantifier of the NP names the boundary of the NP. Bare plurals and mass nouns are unbounded because they do not contain determiners or quantifiers naming their boundaries» (cfr. también Rijkhoof, 1991).

3.3 Así, el diferente contenido aspectual, justificado por las diferentes posibilidades sintagmáticas, cs lo que conduce a la distinción de adjetivos y participios en casos como:

«(17) a) Un museo muy visitado (por los turistas)

b) Un filete muy quemado (*por el cocinero)»

y que Bosque $(1990,195)$ explica en los siguientes términos:

«visitado es una forma verbal, mientras que quemado es en (17b) un adjetivo perfectivo (no truncado), lo que explica que no admita complementos agentes (...) El planteamiento que hemos presentado permite hacer una predicción interesante: los verbos transitivos que posean argumentos eventivos podrán aceptar la interpretación distributiva de muy en sus participios (...) y al mismo tiempo podrán aceptar la interpretación aspectual de muy en los adjetivos perfectivos derivados de ellos (truncados o no), puesto que poseen el argumento eventivo que esta interpretación requiere. Esto es exactamente lo que ocurre. (18) tiene las dos interpretaciones:

(18) Una hamburguesa muy hecha» 
De cualquier forma, la relevancia sintáctica de la «telicidad» o «determinación» en los nombres está fuera de duda desde que se señaló» su peso en el logro de construcciones en mayor o menor grado transitivas (cfr. Hopper \& Thompson, 1980; Moure, 1991).

Resumiendo, cabe defender una concepción sobre el rango gramatical del aspecto en la órbita de la Lingüística general si fundamentamos aquel estatus en las proyecciones sintagmáticas, en las implicaciones sintácticas. Las distintas lenguas particulares formalizarán gramaticalmente el aspecto si se observan tales repercusiones, y ahí radica la generalidad de la categoría. Ahora bien, los modos de expresión, así como las opciones sobre los contenidos serán muy diversos.

En relación con lo anterior, y desde los presupuestos que he venido esbozando no es posible mantener la distinción aspecto vs. Aktionsart ni en el ámbito nocional ni tampoco por criterios que alcancen a mecanismos de expresión material.

No cabe la distinción en el ámbito nocional dado que se trata de una única área relativa a la aspectualidad que integra contenidos con posibilidad de sistematización jerárquica o de otro tipo; pero no agrupables por pautas de objetividad y subjetividad que remiten a situaciones concretas de lenguas particulares. Ya se ha señalado la escasa fiabilidad de dicho criterio, y buena prueba de ello es que los «contenidos aspectuales objetivos» (Aktionsart) son en muchos casos modificados por el «punto de vista» en secuencias concretas (cfr. «estoy siendo yo misma», en donde la estatividad de «ser» se halla modificada por el punto de vista «progresivo»; véase nota 20). De ahí que se haya desarrollado la tendencia de aproximarse al aspecto por la vía de la «composicionalidad», teniendo en cuenta el contex to y la sintagmática, hasta el extremo de que llega a considerarse — como lo hace Verkuyl (1972, 40)— que

«the term 'Aspects' applies to configurations of categories fitting into certain schemata. If categories come under these schemata we can say that the node dominating these categories is the node to which the Aspects should be assigned. Thus, in our linguistic theory the term 'Aspects' can be considered a derived notion»

Ya he aludido a los peligros que entraña una interpretación extrema de la composicionalidad del aspecto, así como al riesgo que comporta limitar la caracterización de la categoría a lo que únicamente son resultados de valores. De cualquier forma, el acercamiento composicional ha favorecido la ruptura con la atribución de «rasgos aspectuales inherentes» a los verbos y ha facilitado la reflexión, en el sentido opuesto, sobre la «potencialidad aspectual», o en términos de Mourelatos $(1978,419)$ «multivalencia aspectual» de los verbos.

No se habla ya, pues, de aspecto y Aktionsart como clases de contenidos aspectuales, sino que lo adecuado es referirse a la aspectualidad con significa- 
dos que pueden sistematizarse de diversos $\operatorname{modos}{ }^{34}$, pero sin que ello constriña las posibilidades de proyección material del aspecto en las lenguas. En este sentido, concebir la categoría asociándola a múltiples valores potenciales que se desarrollan una vez que el verbo se combina en estructuras, parece la opción idónea. Antes que interpretarla exclusivamente a base de los resultados que se observan en tales estructuras. Ya he señalado que esos productos (presencia de funciones como C.D., C.C., determinación, tests distribucionales, etc.) son indicios que justifican la identificación del aspecto, pero que no lo caracterizan.

En cuanto al criterio relativo a la expresión de los contenidos aspectuales para distinguir aspecto de Aktionsart es absolutamente inadecuado no sólo desde el prisma de la Lingüística general (por la variedad interlingüística), sino también desde la óptica de la Lingüística descriptiva - ya que un mismo contenido aspectual puede expresarse por procedimientos diversos en una misma lengua-. La asunción, por otra parte bastante extendida en la actualidad, de que aspecto y Aktionsart no son parangonables al situarse en niveles metodológicos y conceptuales

34 Hay propuestas de clasificaciones jerárquicas, y las hay también de clasificaciones matriciales que permiten el entrecruzamiento de propiedades al tiempo que anulan la prelación entre contenidos.

Comrie (1976) ofrece una organización jerárquica al interpretar en sentido arbóreo los significados aspectuales (véase apdo. 1.2. de este trabajo; cfr. Comrie, 1976, 25, y cap. 2).

Brinton (1988), después de valorar (pp. 32 y ss.) distintas clasificaciones (de Vendler, 1967 y Mourelatos, 1978, entre otras), se decanta por una visión plana de las categorías aspectuales definidas a base de rasgos (sobre todo las categorías integradas en la Aktionsart). Refleja, así, dichas categorías en los cuadros siguientes (págs. 53 y 56):

\begin{tabular}{|c|c|c|c|}
\hline & Category & Subcategory & Formal markers \\
\hline I. & perfective & & simple forms \\
\hline \multirow[t]{4}{*}{2.} & imperfective & progressive & be V-ing \\
\hline & & continuative & continue to $\mathrm{V}$, \\
\hline & & & $\mathrm{V}$-ing; keep on \\
\hline & & & V-ing \\
\hline & phase & ingressive & start to $\mathrm{V}, \mathrm{V}$-ing; \\
\hline & & & begin to $\mathrm{V}, \mathrm{V}$-ing \\
\hline & & egressive & stop $\mathrm{V}$-ing; cease \\
\hline & & & to $\mathrm{V}, \mathrm{V}$-ing \\
\hline & & & finish V-ing \\
\hline \multirow{3}{*}{\multicolumn{2}{|c|}{ 4. habitual }} & & (be) used to $\mathrm{V}$; be \\
\hline & & & accustomed to $\mathrm{V}$ \\
\hline & & & $\begin{array}{l}\text { simple forms } \\
\text { have V-en }\end{array}$ \\
\hline
\end{tabular}


muy distintos ${ }^{35}$, es un argumento definitivo contra el mantenimiento de la dicotomía. La terminología, no obstante, sigue vigente lo que añade nuevos problemas de equívocos a los ya derivados de la debilidad de la misma dicotomía. Hay que rechazar, pues, la distinción y abandonar la nomenclatura.

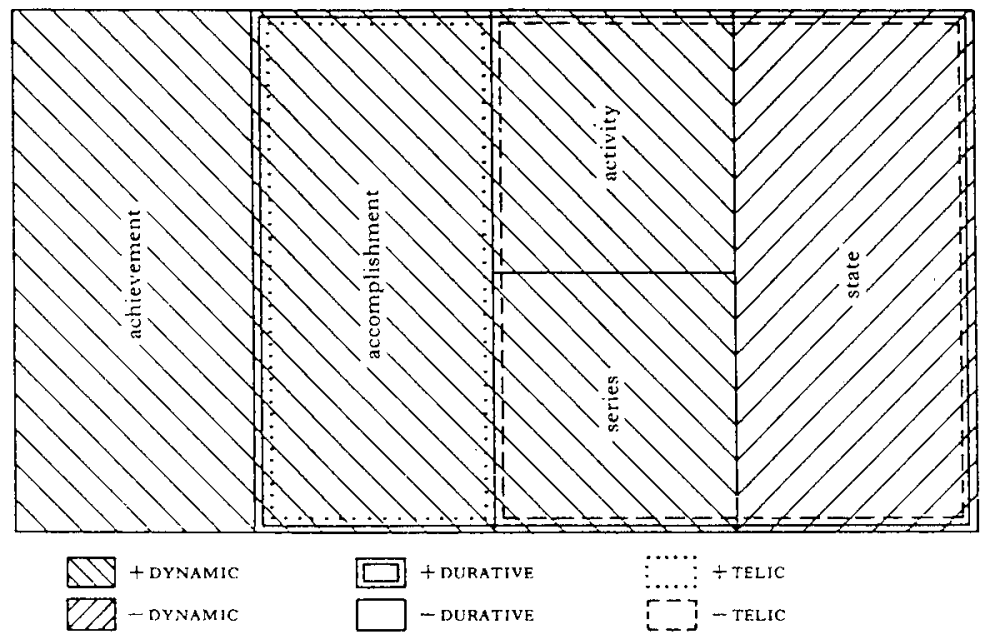

35 Las palabras de, por ejemplo, Kotsinas $(1989,36)$ transparentan el nivel metodológico de procedimiento que corresponde a la Aktionsart, frente al nivel metodológico de concepto teórico que se otorga al aspecto:

«Instead it (the aspect, M.F.P.) is sometimes expressed by way of the aktionsart of the verb in words like 'die', 'wait' and so on and sometimes by phrases meaning 'sit and write' (be writing), 'stand and look' (be looking), 'keep on to play' (be playing) for imperfective aspect and 'write down' (write), 'burn up' (burn) for perfective aspect» (subrayado mío) 


\section{REFERENCIAS BIBLIOGRÁFICAS}

ALARCOS, E. (1949), «Estructura del verbo español», Estudios de gramática funcional del español, Madrid, Gredos, 19803, 50-94.

BOSQUE, I. (1990), «Sobre el aspecto en los adjetivos y en los participios», Tiempo y aspecto en español (ed. I. Bosque), Madrid, Cátedra, 1990, 177-214.

BRINTON, L.J. (1987), «The aspectual nature of states and habits», Folia Linguistica, XXI/2-4, 1987, 195-214.

- (1988), The development of English aspectual systems. Aspectualizers and post-verbal particles, Cambridge, Cambridge University Press, 1988.

COHEN, D. (1989), L'aspect verbal, Paris, P.U.F., 1989.

COMRIE, B. (1976), Aspect. An introduction to the study of verbal aspect and related problems, Cambridge, Cambridge University Press, 1976.

COSERIU, E. (1978), «Aspect verbal ou aspects verbaux? Quelques questions de thorie et de mthode», La notion d'aspect (ed. J. David \& R. Martin), Metz, Universit de Metz, 1980, 13-25.

DAHL, O. (1985), Tense and aspect systems, Oxford, Blackwell, 1985.

DESCLS, J.-P. (1978), «Construction formelle de la catgorie grammatical de l'aspect», La notion d'aspect (ed. J. David \& R. Martin), Metz, Universit de Metz, 1980, 195-237.

FERNÁNDEZ PÉREZ, M. (1987), «La importancia de las corrientes de investigación en la configuración de la teoría lingística: un ejemplo con las llamadas categorías gramaticales», Verba, 14, 1987, 75-101.

- (1990), «Consideración del aspecto en español a partir de sus implicaciones sintácticas», La descripción del verbo español (coor. G. Wotjak \& A. Veiga), anexo 32 de Verba, Santiago de Compostela, 1990, 127-131.

- (1991 a), «Consideraciones sobre el género en español», Homenaje a Constantino Garcia, Santiago de Compostela, Universidad, 1991, 149-162.

- (1991 b), «Sobre el concepto de morfema y el ámbito de la Morfología», Verba, $18,1991,27-68$.

FORSYTH, J. (1970), A Grammar of Aspect. Usage and meaning in the russian verb, Cambridge, Cambridge University Press, 1970.

FRANCKEL, J.-J. \& Paillard, D. (1991), «Discret-dense-compact; vers une typologie opratoire», Travaux de Linguistique et de Philologie, XXIX, 1991, 103-136.

FUCHS, C. (1991), «Les typologies de procs: une carrefour thorique interdisciplinaire», Travaux de Linguistique et de Philologie, XXIX, 1991, 9-17.

GARCÍA HERNÁNDEZ, B. (1977), «El sistema del aspecto verbal en latín y en español», Studia Philologica Salmanticensia, 1, 1977, 65-114.

GOSSELIN, L., FRANCOIS, J. ET ALII (1991), «Les types de procs; des verbes aux prdications", Travaux de Linguistique et de Philologie, XXIX, 1991, 19-86.

HEINMKI, O. (1984), «Aspect in Finnish», Aspect Bound. A voyage into the realm of Germanic, Slavonic and Finno-Ugrian aspectology (ed. C. de Groot \& H. Tommola), Dordrecht, Foris, 1984, 153-177.

HOPPER, P.J. \& THOMPSON, S.A. (1980), «, Fransitivity in Grammar and Discourse», Language, 56/2, 1980, 251-299. 
KOTSINAS, U.-B. (1989), «Come, Stay, Finish. On the development of Aspect Markers in Interlanguage and Pidgin/Creole Languages», Proceedings of the Second Scandinavian Symposium on Aspectology (ed. L.-G. Larsson), UPPSALA, ALMQVIST \& WIKSELL INTER., 1989, 33-48.

LINDSTEDT, J. (1985), On the semantics of tense and aspect in Bulgarian, Helsinki, University of Helsinki, 1985.

MOURE, T. (1991), «El contenido aspectual telicidad en las clusulas biactanciales del español», Verba, 18, 1991, 353-374.

MOURELATOS, A.P.D. (1978), «Events, processes, and states», Linguistics and Philosophy, 2, 1978, 415-434.

PLATZACK, Chr. (1979), The semantic interpretation of aspect and Aktionsarten. A Study of internal time reference in Swedish, Dordrecht, Foris, 1979.

RIJKHOOF, J. (1991), «Nominal Aspect», Journal of Semantics, 8, 1991, 291 1-309.

SASSE, H.-J. (1991), «Aspect and Aktionsart. A reconciliation», Belgian Journal of Linguistics, 6, 1991, 31-45.

SELJAKIN, M. (1984), «On the essence of the category of aspectuality and its lexical-semantic level in Russian», Aspect Bound. A voyage into the realm of Germanic, Slavonic and Finno-Ugrian aspectology (ed. C. de Groot \& H. Tommola), Dordrecht, Foris, 1984, 39-52.

SHI, Z. (1990), «On the inherent aspectual properties of NPs, vebs, sentences and the decomposition of perfectivity and inchoativity», Word, 41/1, 1990, 47-67.

SLAWOMIRSKI, J. (1983), «La posición del aspecto en el sistema verbal español», R.S.E.L., 13/1, 1983, 91-121.

SMITH, C.S. (1983), «A theory of aspectual choice», Language, 59, 1983, 479-501.

TORREGO, E. (1988), «Restricciones de la categoría verbal «aspecto» sobre los elementos de duración en latín», Minerva, 2, 1988, 259-278.

VEIGA, A. (1991), Condicionales, concesivas y modo verbal en español, anexo 34 de Verba, Santiago de Compostela, 1991.

VENDLER, Z. (1967), Linguistics in philosophy, N. York, Cornell University Press, 1967.

VERKUYL, H.J. (1972), On the compositional nature of the aspects, Dordrecht, Reidel, 1972. 